\title{
Debris Flow Hazard Zoning Based on Numerical Simulation in the Wenchuan Earthquake Meizoseismal Areas
}

\author{
Wang Jun ${ }^{1,2, a^{*}, Y u ~ Y a{ }^{3, b}}$ \\ ${ }^{1}$ Guangzhou Institute of Geography, Guangzhou 510070, China; \\ ${ }^{2}$ Guangdong Open Laboratory of Geospatial Information Technology and Application; Guangzhou \\ 510070, China; \\ ${ }^{3}$ Institute of Mountain Hazards and Environment, Chinese Academy of Sciences, Chengdu 610041, \\ China \\ a*email: wangjun210@mails.ucas.ac.cn \\ bemail: yuyan10@mails.ucas.ac.cn
}

Keywords: Wenchuan earthquake; debris flow; hazard zoning; dynamic process; numerical simulation

Abstract: The Wenchuan earthquake triggered a large number of landslides and collapses in the quake-hit areas, which left a tremendous amount of loose deposits on the slopes and on the valley bottoms. The debris flow pregnant environment has changed dramatically, making the hazard level of debris flow increased greatly. After the earthquake, debris flow hazards occurred frequently and effective hazard assessment of debris flow has become extremely important. The Wu Xianmiao gully in Du Jiangyan city, located in the meizoseismal areas, was selected as the study area. Based on the research of disaster - pregnant environment, a 3-D debris flow numerical simulation platform was established first, then, the hydrological frequency analysis method and the empirical model were used to calculate the debris flow process under the different design frequency $(5 \%, 2 \%$ and $1 \%)$, the final accumulated scope and depth of debris flow were simulated by the Flow3D software, and the debris flow hazard zonings under the different design frequency were mapped finally.

\section{Introduction}

Debris flow is a common natural phenomenon in mountain areas and often brings serious casualties and property loss each year, which seriously affects the economic and social development of mountain areas ${ }^{[1]}$. Especially in the Wenchuan earthquake-stricken areas, the earthquake triggered a large number of loose solid materials resulting in the debris flow pregnant environment and the hazard level of debris flow increased greatly. In the seven years since the earthquake, intense rainfall events have triggered massive debris flows on several occasions (such as the Zhouqu debris flow, the Wenjia gully debris flow and the Hongchun gully debris flow), causing serious casualties and loss of property ${ }^{[2] \sim[4]}$.

As an important means of the disaster non-engineering mitigation, the effective hazard assessment of debris flow has become extremely important. Therefore, this paper focus on the debris flow hazard mapping in the earthquake-hit areas and conduct a case study .

\section{Study area}

The $\mathrm{Wu}$ Xianmian gully in Du Jiangyan city, located in the meizoseismal areas of Wenchuan earthquake, China, was selected as the study area (Figure 1). The seismic intensity of the study area was XI, which was the maximum seismic intensity of the Wenchuan earthquake. The area extends from $31^{\circ} 05^{\prime} 21^{\prime \prime} \mathrm{N}$ to $31^{\circ} 05^{\prime} 53^{\prime \prime} \mathrm{N}$ latitude and $103^{\circ} 35^{\prime} 22^{\prime \prime} \mathrm{E}$ to $103^{\circ} 36^{\prime} 01^{\prime \prime} \mathrm{E}$ longitude, covering an area of $1.24 \mathrm{~km}^{2}$, with a population of 20 inhabitants. The elevation range of the Wu Xianmian gully is between $965 \mathrm{~m}$ and $2140 \mathrm{~m}$, the main channel gradient is $255 \%$, and the main channel length is approximately $1.8 \mathrm{k} \mathrm{m}$. 
Geomorphologically, the study area belongs to the Longmenshan Mountains. The study area has strong tectonic movement and strong erosion, where the main channel is "V"-shaped. The main slope gradient interval of the gully is $30^{\circ}$ to $40^{\circ}$, accounting for $68.85 \%$ of the entire study area.

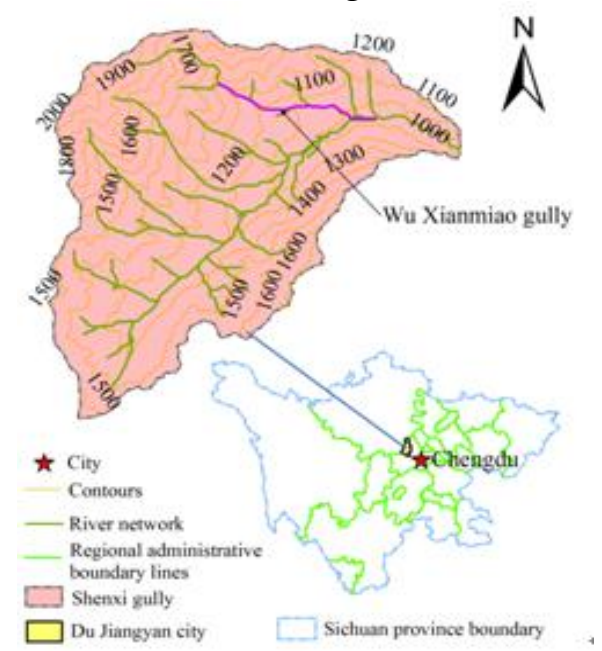

Fig. 1 The location of the study area

\section{The disaster-pregnant environment of debris flows}

The Wenchuan earthquake triggered a tremendous amount of loose deposits on the slopes and on the valley bottoms. These deposits were remobilized in the form of debris flows in the years following the earthquake. Intensive field investigations indicated that the volume of loose deposits amounted to more than $50 \times 10^{4} \mathrm{~m}^{3}$. The abundant loose deposits are shown in Figure 2(a). The channel micro-topography was altered due to erosion and accumulation of loose deposits. The blockage of the gully channel is severe (Figure2 (b)) and may create a cascade that would be followed by damming, dam breakage and debris flows.

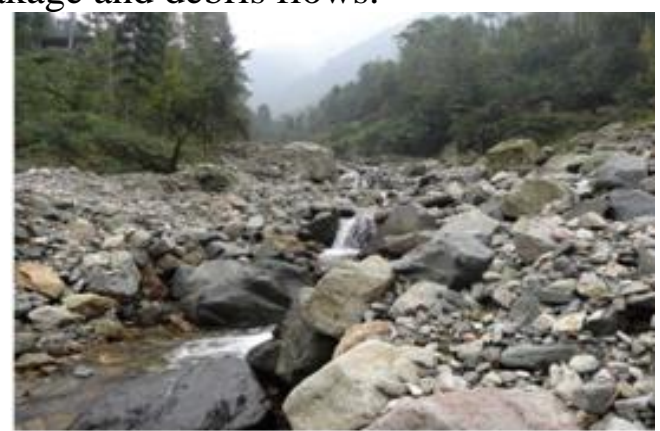

(a) The loose deposits in the gully

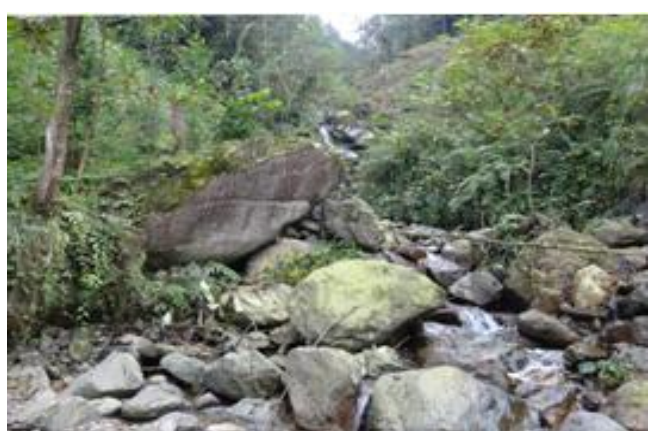

(b) The blockage of the main channel

Fig. 2 The loose solid materials and the serious blocking phenomenon in the Wu Xianmiao gully

The disaster - pregnant environment of the study area changed dramatically because of the earthquake and the activity frequency of debris flow pre- and post-earthquake also changed sharply. Before the Wenchuan Earthquake, the study area had no debris flows. However, after the earthquake, this area occurred debris flow in 2010 and 2012, affecting the post-earthquake reconstruction and sustainable development.

\section{The 3-D platform of debris flow numerical simulation}

There are two ways to access to the 3-D digital terrain, one is use the surveying and mapping instruments directly to obtain 3-D digital terrain, such as GPS, total station, terrestrial 3D laser scanne, the other is by means of aerial photography, obtain the high resolution aerial images and then extract the 3-D digital terrain from aerial images indirectly. In this study, base on geographic information system (GIS), vector the paper topographic map of the Wu Xianmiao gully and obtain elevation points data of the terrain. Write the corresponding program to import the elevation points data into Flow3D 
software, the 3-D platform of debris flow numerical simulation can be obtain, which is shown in Figure 3.

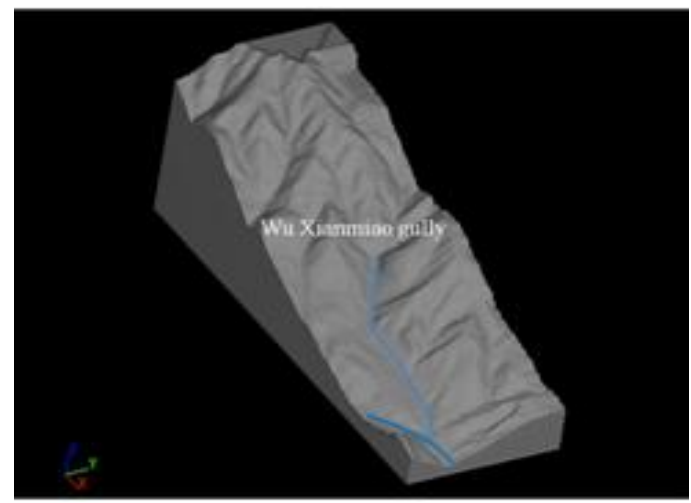

Fig. 3 The 3-D platform of debris flow numerical simulation in Wu Xianmiao gully

\section{The peak discharge and flood hydrograph under the different design frequency}

The peak discharge under different design frequency is calculated by the formula proposed by China Institute of Water Resources and Hydropower Research:

$$
Q_{p}=0.278 \phi i F=0.278 \phi \frac{s}{\tau^{n}} F
$$

where, ${ }^{Q_{p}}$ is the peak discharge $\left(\mathrm{m}^{3} / \mathrm{s}\right), \phi_{\text {is }}$ the peak discharge coefficient: $\phi=f\left(\mu, \tau^{n}\right)$,aa ${ }^{\mu}$ is the runoff coefficient, $F$ is watershed area $\left(\mathrm{km}^{2}\right), s$ is the rain force $(\mathrm{mm} / \mathrm{h})$, and $\tau$ is the concentration time $(h)$, as:

$$
\tau^{n}=f(m, s, \quad J, L)
$$

where, ${ }^{n}$ is the rain index, $J$ is the channel gradient (\%o), $L$ is the main channel length $(\mathrm{km})$, and $m$ is the confluence parameter which can be calculated by the formula:

$$
m=0.221 \theta^{0.204}
$$

where, $\theta$ is watershed characteristic parameter, can be expressed as follows:

$$
\theta=\frac{L}{J^{1 / 3} F^{1 / 4}}
$$

Above parameters is obtained by handbook of the storm flood calculation in Sichuan province (1984), and the key parameters are listed in Table 1.

\begin{tabular}{ccccccc}
\hline Watershed & $\begin{array}{c}\text { Watershed } \\
\text { area } \\
/ \mathrm{F} / \mathrm{km}^{2}\end{array}$ & $\begin{array}{c}\text { Channel } \\
\text { length } \\
/ \mathrm{L} / \mathrm{km}\end{array}$ & $\begin{array}{c}\text { Channel } \\
\text { gradient } \\
/ \mathrm{J} / \% 0\end{array}$ & $\begin{array}{c}\text { Watershed } \\
\text { characteristic } \\
\text { parameter } / \theta\end{array}$ & $\begin{array}{c}\text { Confluence } \\
\text { parameter } \\
/ \mathrm{m}\end{array}$ & $\begin{array}{c}\text { Runoff } \\
\text { coefficient } \\
/ \mu\end{array}$ \\
\hline $\begin{array}{c}\mathrm{Wu} \\
\text { Xianmiao }\end{array}$ & 1.24 & 1.8 & 0.255 & 2.690 & 0.270 & 3.456 \\
\hline
\end{tabular}

Table 1 The parameters of the watershed characteristic parameters in the study area

According to the handbook of the storm flood calculation in Sichuan province (1984), the peak discharge under the different design frequency $(5 \%, 2 \%$ and $1 \%)$ can be obtained. After this, the typical flood amplification method is used to calculate the design flood hydrograph.

\section{Calculation of debris flow discharge hydrograph under the different design frequency}

The debris flow runoff process is controlled by the water flow runoff and the amounts of started loose materials, which can be obtained by combining water flow process and appropriate debris flow parameters. Based on a large number of experiments and field observations, Chinese debris flow scholars proposed the empirical formula calculating debris flow discharge, which is widely used in China ${ }^{[17]}$ : 


$$
Q_{C}=(1+\phi) Q_{P} \mathrm{~g} D_{C}
$$

in which $Q_{C}$ is the debris flow peak discharge; $Q_{P}$ is the water flow peak discharge; $D_{C}$ is the channel blockage parameter, its empirical value is shown in Table 4; $\varphi$ is the sediment correction coefficient, can be calculated by the formula:

$$
\phi=\left(\gamma_{C}-\gamma_{W}\right) /\left(\gamma_{H}-\gamma_{C}\right)
$$

in which $\gamma_{C}$ and $\gamma_{W}$ are the unit weight of debris flow and water, respectively; ${ }_{H}$ is the weight of solid materials in debris flow, always is $27 \mathrm{kN} / \mathrm{m}^{3}$.

\begin{tabular}{ccccc}
\hline $\begin{array}{c}\text { The degree of } \\
\text { blockage }\end{array}$ & No blockage & Slight blockage & $\begin{array}{c}\text { Moderate } \\
\text { blockage }\end{array}$ & Severe blockage \\
\hline$D_{C}$ & 1 & 1.5 & 2 & 2.5 \\
\hline
\end{tabular}

Table 2 The channel blockage parameter ${ }^{[17]}$

To this end, the debris flow runoff process can be obtained combining the water flow confluence process and the empirical formula. Finally, the calculated parameters are shown in Table 3 and debris flow processes under the different design frequency $(5 \%, 2 \%$ and 1\%) are shown in Figure 4.

\begin{tabular}{ccccccc}
\hline $\begin{array}{c}\text { Design } \\
\text { frequency }\end{array}$ & $\begin{array}{c}\text { Blockage } \\
\text { parameter/ } / D_{C}\end{array}$ & $\begin{array}{c}\text { The density } \\
\text { of debris } \\
\text { flow/ } \\
\rho_{\mathrm{d}} / \mathrm{g} / \mathrm{cm}^{3}\end{array}$ & $\begin{array}{c}\text { The density } \\
\text { of loose } \\
\text { materials } / \rho_{\mathrm{H}} \\
/ \mathrm{g} / \mathrm{cm}^{3}\end{array}$ & $\begin{array}{c}\text { Sediment } \\
\text { correction } \\
\text { coefficient/ } /\end{array}$ & $\begin{array}{c}\text { Water flow } \\
\text { peak } \\
\text { discharge } \\
/ \mathrm{Qp} / \mathrm{m}^{3} / \mathrm{s}\end{array}$ & $\begin{array}{c}\text { Debris flow } \\
\text { peak } \\
\text { discharge } \\
\mathrm{Qc} / \mathrm{m}^{3} / \mathrm{s}\end{array}$ \\
\hline $5 \%$ & 2.5 & 1.717 & 2.70 & 0.737 & 36.26 & 157.35 \\
$2 \%$ & 2.5 & 1.717 & 2.70 & 0.737 & 42.936 & 186.33 \\
$1 \%$ & 2.5 & 1.717 & 2.70 & 0.737 & 47.86 & 207.70 \\
\hline
\end{tabular}

Table 3 The peak discharge of debris flow under the different design frequency in the study area

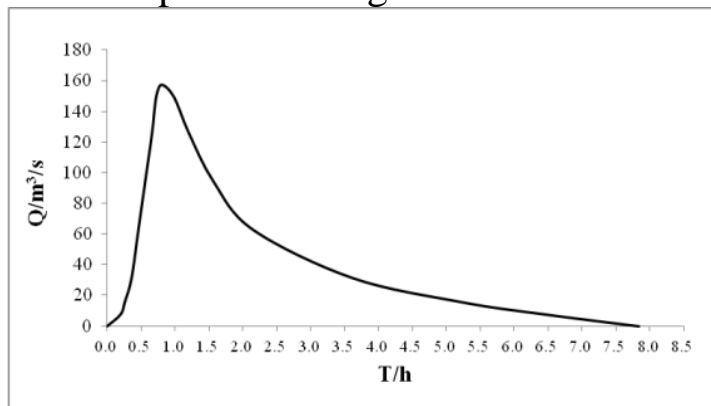

(a) $5 \%$

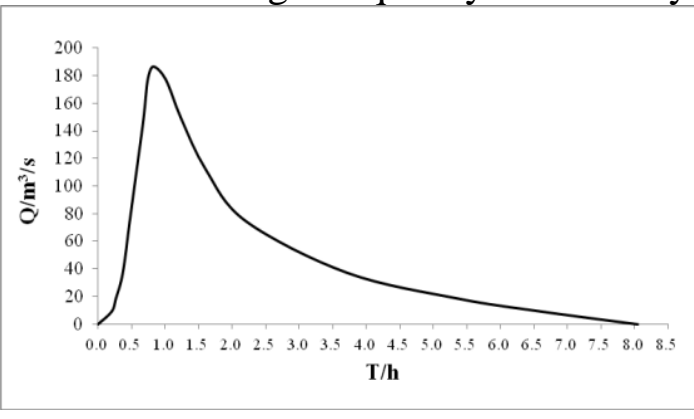

(b) $10 \%$

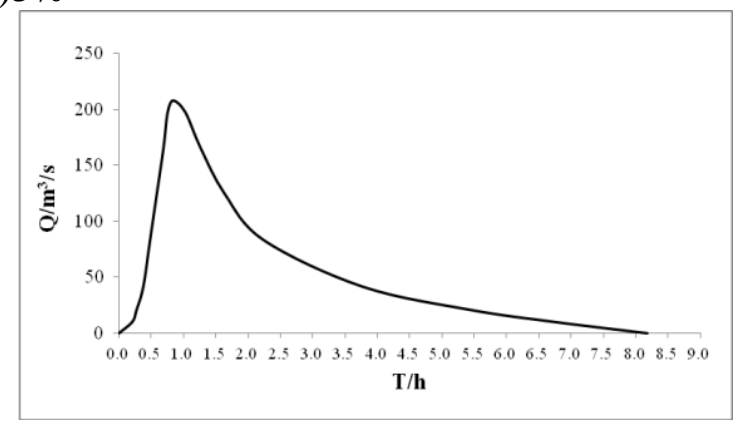

(c) $1 \%$

Fig. 4 The discharge hydrograph of debris flow under the different design frequency in the Wu Xianmiao gully 


\section{Numerical simulation and hazard zonings of debris flow}

In Flow3D, use the debris flow discharge hydrograph as the initial condition and use the 3-D platform of debris flow numerical simulation as boundary condition to conduct debris flow numerical simulation. The debris flow parameters used in numerical simulation is shown in Table 4.

\begin{tabular}{ccccc}
\hline Debris flow property & $\begin{array}{c}\text { Density } \\
/ \mathrm{g} / \mathrm{cm}^{3}\end{array}$ & $\begin{array}{c}\text { Yield stress } \\
/ \mathrm{Pa}\end{array}$ & $\begin{array}{c}\text { Coefficient of } \\
\text { viscosity }\end{array}$ & Bed roughness \\
\hline Bingham & 1.717 & 20 & 0.5 & 0.1 \\
\hline
\end{tabular}

Table 4 The debris flow parameters used in numerical simulation

Through debris flow numerical simulation, the scope and depth of debris flow deposits can be obtained.

Use the debris flow depth as the parameter to conduct debris flow hazard zonings, the hazard classified criteria in the study area is show in Table 5.

\begin{tabular}{cc}
\hline Debris flow hazad class & Depth/m \\
\hline Low hazard degree & $\mathrm{h} \leq 1 \mathrm{~m}$ \\
Moderate hazard degree & $1 \mathrm{~m}<\mathrm{h} \leq 3 \mathrm{~m}$ \\
High hazard degree & $3 \mathrm{~m}<\mathrm{h} \leq 6$ \\
Extremely high hazard degree & $\mathrm{h}>6 \mathrm{~m}$ \\
\hline
\end{tabular}

Table 5 The debris flow hazard classified criteria in the study area

Base on the debris flow simulation and the hazard classified criteria, the debris flow hazard zonings under the different design frequency in the study area is shown in Figure 5.

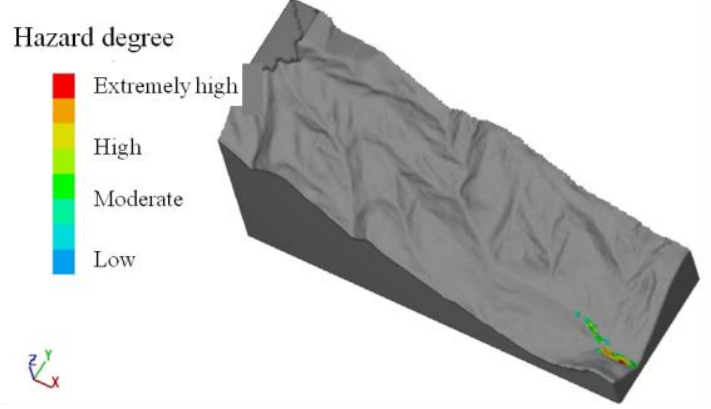

(a) $5 \%$

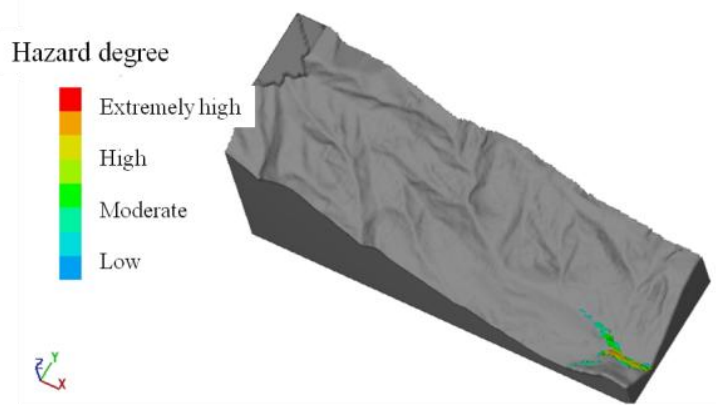

(b) $10 \%$

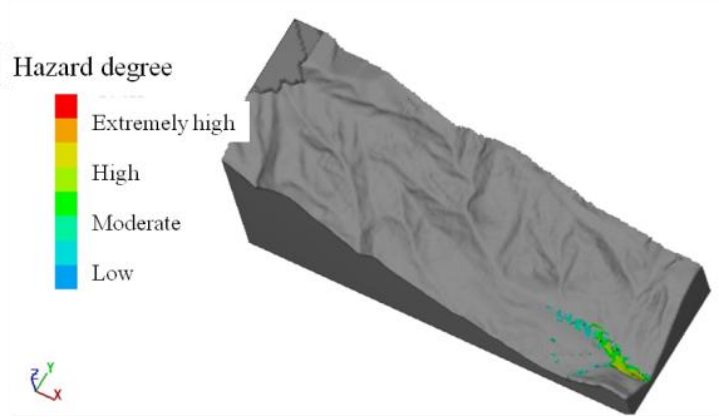

(c) $1 \%$

Fig. 5 The debris flow hazard zonings under the different design frequency in the study area

\section{Acknowledgements}

Financial support was provided by talent fund of Guangzhou Institute of Geography (NO. 2015157ZGD), National Natural Science Foundation (NO. 41372331), the international cooperation project of the Ministry of Science and Technology (NO. 2013DFA21720), and Guangdong province water conservancy science and technology innovation project (NO. 2011-19). 


\section{References}

[1] J. Wang, Y. Yu, S. Yang, G. H. Lu, G. Q. Ou, A modified certainty coefficient method (M-CF) for debris flow susceptibility assessment: A case study for the Wenchuan earthquake meizoseismal areas, Journal of Mountain Science. 11(5) (2014) 1286-1297.

[2] B. Yu, Y. Ma and F. Y. Wu, Investigation of severe debris flow hazards in Wenjia gully of Sichuan province after the Wenchuan earthquake, Journal of Engineering Geology 18(6) (2010) 827-836.

[3] Y. You, J. F. Liu and X. Z. Chen, Debris flow and its characteristics of Subao river in Beichuan county after 5.12 Wenchuan earthquake, Journal of Mountain Science, 28(3)(2010) 358-366.

[4] J. Wang, Y. Yu, H. L. Pan, C. Qiao, G. Q. Ou, Debris flow formation process and critical hydrodynamic conditions in the meizoseismal areas of Wenchuan earthquake. Journal of Mountain Science 12(3) (2005) 699-710. 